Structural investigation of quaternary layered oxides upon Na-ion deinsertion

Angelo Mullaliu, ${ }^{1,2}$ Kazutoshi Kuroki, ${ }^{3}$ Marlou Keller, ${ }^{1,2}$ Kei Kubota, ${ }^{3}$ Daniel Buchholz,,${ }^{1,2}$ Shinichi Komaba, ${ }^{3, *}$ and Stefano Passerini ${ }^{1,2, *}$

${ }^{1}$ Helmholtz Institute Ulm (HIU), Helmholtzstrasse 11, 89081 Ulm, Germany

${ }^{2}$ Karlsruhe Institute of Technology (KIT), P.O. Box 3640, 76021 Karlsruhe, Germany

${ }^{3}$ Department of Applied Chemistry, Tokyo University of Science, 1-3 Kagurazaka, Shinjuku, Tokyo162-8601, Japan

Keywords: $\mathrm{Na}_{0.76} \mathrm{Mn}_{0.5} \mathrm{Ni}_{0.3} \mathrm{Fe}_{0.1} \mathrm{Mg}_{0.1} \mathrm{O}_{2}$; XRD; crystalline structure, Na removal; Na-ion batteries

\title{
*Corresponding Authors:
}

komaba@rs.kagu.tus.ac.jp

stefano.passerini@kit.edu 
According to Figure S1, the best fit results when the mixed $\mathrm{NiMgO}$ is constituted by a $\mathrm{Ni} / \mathrm{Mg}$ ratio equal to $0.6 / 0.4$. Fit goodness parameters $\left(\mathrm{R}_{\mathrm{B}}\right.$ and $\left.\mathrm{R}_{\mathrm{F}}\right)$ for each phase are satisfactory.

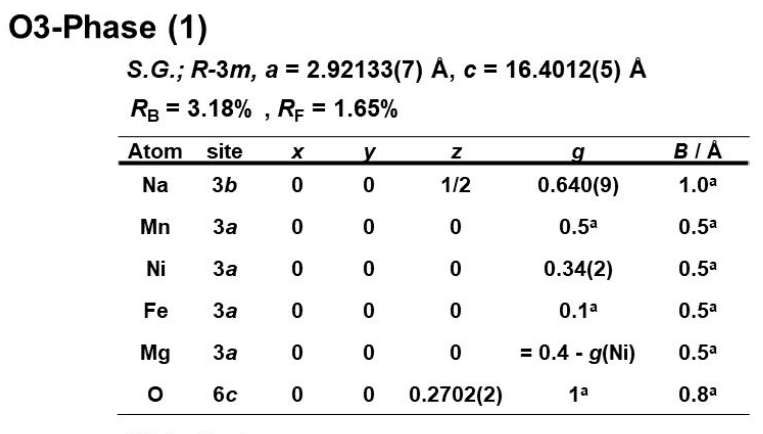

a Not refined

\section{P2-Phase}

S.G.; $P 6_{3} / m m c, a=2.89600(8) \mathrm{A}, c=11.1217(3) \mathrm{A}$ $R_{\mathrm{B}}=4.02 \%, R_{\mathrm{F}}=1.88 \%$

\begin{tabular}{ccccccc}
\hline Atom & site & $X$ & $y$ & $z$ & $g$ & $B / A$ \\
\hline $\mathrm{Na}_{\text {face }}$ & $2 b$ & 0 & 0 & $1 / 4$ & $0.187(10)$ & $1.0^{\mathrm{a}}$ \\
$\mathrm{Na}_{\text {edge }}$ & $2 c$ & $1 / 3$ & $2 / 3$ & $1 / 4$ & $0.441(15)$ & $1.0^{\mathrm{a}}$ \\
$\mathrm{Mn}$ & $2 a$ & 0 & 0 & 0 & $0.5^{\mathrm{a}}$ & $0.5^{\mathrm{a}}$ \\
$\mathrm{Ni}$ & $2 a$ & 0 & 0 & 0 & $0.30(2)$ & $0.5^{\mathrm{a}}$ \\
$\mathrm{Fe}$ & $2 a$ & 0 & 0 & 0 & $0.1^{\mathrm{a}}$ & $0.5^{\mathrm{a}}$ \\
$\mathrm{Mg}$ & $2 a$ & 0 & 0 & 0 & $=0.4-g(\mathrm{Ni})$ & $0.5^{\mathrm{a}}$ \\
0 & $4 f$ & $1 / 3$ & $2 / 3$ & $0.5836(7)$ & $1.0^{\mathrm{a}}$ & $0.8^{\mathrm{a}}$ \\
\hline \multicolumn{6}{l}{ Not refined }
\end{tabular}

$$
\mathrm{Ni}_{0.6} \mathrm{Mg}_{0.4} \mathrm{O}
$$

S.G.; Fm-3m, $a=4.1900(3)$ A

$R_{\mathrm{B}}=\mathbf{2 . 5 2} \%, R_{\mathrm{F}}=1.40 \%$

\begin{tabular}{ccccccc}
\hline Atom & site & $x$ & $y$ & $z$ & $g$ & $B / A$ \\
\hline $\mathrm{Ni}$ & $4 a$ & 0 & 0 & 0 & $0.59(3)$ & $0.4^{\mathrm{a}}$ \\
$\mathrm{Mg}$ & $4 a$ & 0 & 0 & 0 & $=1-g(\mathrm{Ni})$ & $0.4^{\mathrm{a}}$ \\
0 & $4 b$ & $1 / 2$ & $1 / 2$ & $1 / 2$ & $1.0^{\mathrm{a}}$ & $0.6^{\mathrm{a}}$ \\
\hline \multicolumn{7}{l}{ a Not refined }
\end{tabular}

O3-Phase (2)

S.G.; $R-3 m, a=2.92816(13) \mathrm{A}, c=16.3244(11) \mathrm{A}$

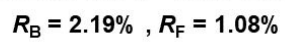

\begin{tabular}{ccccccc}
\hline Atom & site & $x$ & $y$ & $z$ & $g$ & $B / A$ \\
\hline $\mathrm{Na}$ & $3 b$ & 0 & 0 & $1 / 2$ & $0.695(12)$ & $1.0^{\mathrm{a}}$ \\
$\mathrm{Mn}$ & $3 a$ & 0 & 0 & 0 & $0.5^{\mathrm{a}}$ & $0.5^{\mathrm{a}}$ \\
$\mathrm{Ni}$ & $3 a$ & 0 & 0 & 0 & $0.39(3)$ & $0.5^{\mathrm{a}}$ \\
$\mathrm{Fe}$ & $3 a$ & 0 & 0 & 0 & $0.1^{\mathrm{a}}$ & $0.5^{\mathrm{a}}$ \\
$\mathrm{Mg}$ & $3 a$ & 0 & 0 & 0 & $=0.4-g(\mathrm{Ni})$ & $0.5^{\mathrm{a}}$ \\
$\mathrm{O}$ & $6 c$ & 0 & 0 & $0.2705(4)$ & $1^{\mathrm{a}}$ & $0.8^{\mathrm{a}}$ \\
\hline \multicolumn{2}{|c}{ Not refined }
\end{tabular}

\section{P3-Phase}

S.G.; $R 3 m, a=2.89745(9) \mathrm{A}, c=16.7332(6) \mathrm{A}$

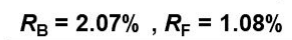

\begin{tabular}{ccccccc}
\hline Atom & site & $x$ & $y$ & $z$ & $g$ & $B / A$ \\
\hline $\mathrm{Na} 1$ & $3 a$ & 0 & 0 & $0.1610(9)$ & $0.335(6)$ & $1.0^{\mathrm{a}}$ \\
$\mathrm{Na} 2$ & $3 a$ & 0 & 0 & $0.8112(13)$ & $=g(\mathrm{Na} 1)$ & $1.0^{\mathrm{a}}$ \\
$\mathrm{Mn}$ & $3 a$ & 0 & 0 & 0 & $0.5^{\mathrm{a}}$ & $0.5^{\mathrm{a}}$ \\
$\mathrm{Ni}$ & $3 a$ & 0 & 0 & 0 & $0.4^{\mathrm{a}}$ & $0.5^{\mathrm{a}}$ \\
$\mathrm{Fe}$ & $3 a$ & 0 & 0 & 0 & $0.1^{\mathrm{a}}$ & $0.5^{\mathrm{a}}$ \\
$\mathrm{Mg}$ & $3 a$ & 0 & 0 & 0 & $=0.4-g(\mathrm{Ni})$ & $0.5^{\mathrm{a}}$ \\
$\mathrm{O} 1$ & $3 a$ & 0 & 0 & $0.3975(3)$ & $1.0^{\mathrm{a}}$ & $0.5^{\mathrm{a}}$ \\
$\mathrm{O} 2$ & $3 a$ & 0 & 0 & $=1-z(01)$ & $1.0^{\mathrm{a}}$ & $0.8^{\mathrm{a}}$ \\
\hline \multicolumn{2}{|c}{ Not refined } & & & & &
\end{tabular}

Figure S1. Relevant Rietveld refinement results for all four phases considered in the pristine powder refinement. Tables include retrieved space group, lattice and atomic parameters, and fit goodness.

Rietveld refinement on the pristine powder has been conducted also by considering 4 phases instead of 5, as shown in Figure S2. While the fit goodness worsens when only 4 phases are considered $\left(R_{w p}\right.$ $(4$ phases $)=9.40 \%$ vs. $\mathrm{R}_{\mathrm{wp}}(5$ phases $)=7.80 \%$ ), the asymmetric profile of the $006_{\mathrm{O} 3}$ diffraction line implies the existence of another O3-type phase having narrower interslab space. 


\section{Four phases model}

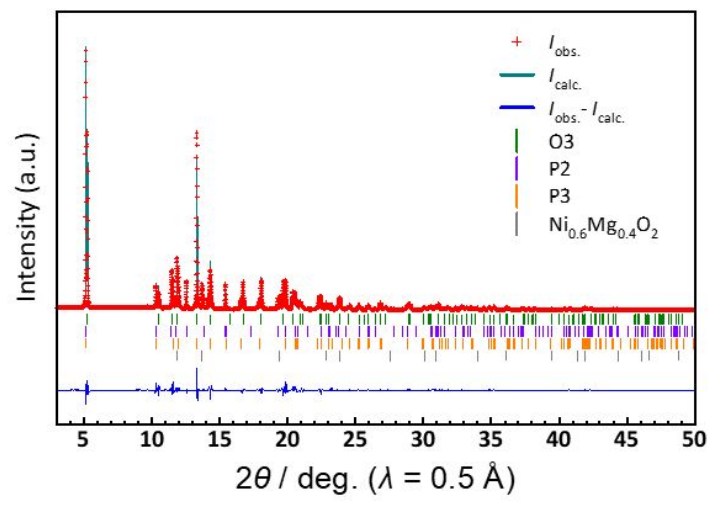

Four phases model

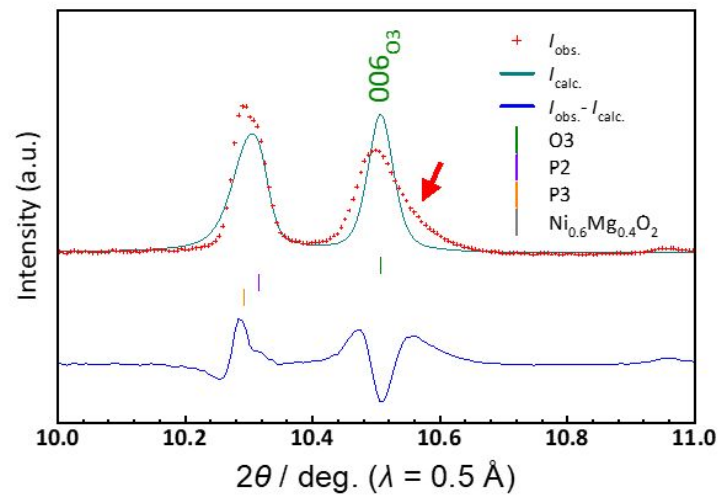

$R_{\text {wp }}=9.40 \%, R_{\mathrm{e}}=1.73 \%, S=5.43$

Figure S2. Rietveld refinement results for the XRD pattern of a pristine sample by using four phases; O3, P3, P2, and $\mathrm{Ni}_{0.6} \mathrm{Mg}_{0.4} \mathrm{O}$. The red arrow suggests the existence of another O3-type phase having narrower interslab space.

From the calculated lattice parameters of $\mathrm{Ni}_{y} \mathrm{Mg}_{1-y} \mathrm{O}$ on the tie line between $\mathrm{NiO}$ and $\mathrm{MgO}$ as well as the refined occupancies of $\mathrm{Ni}$ and $\mathrm{Mg}$, composition of the $\mathrm{Ni} / \mathrm{MgO}$ phase is estimated to be $\mathrm{Ni}_{0.6} \mathrm{Mg}_{0.4} \mathrm{O}$ within standard deviations as shown in Figure $\mathbf{S 3}$.

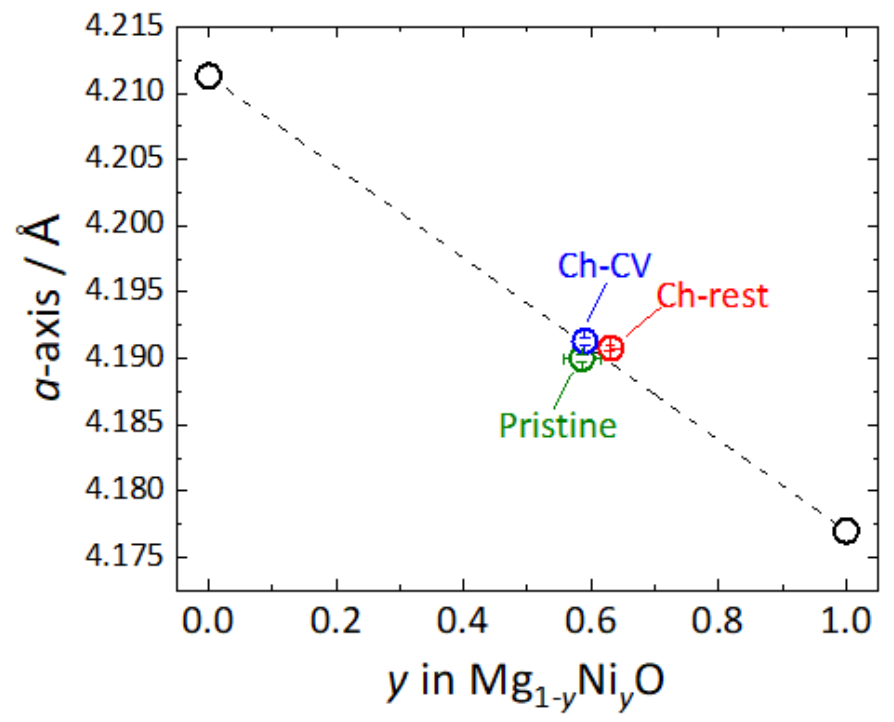

Figure S3. Plot of lattice parameter $a$ vs. Ni content $y$ in $\mathrm{Mg}_{1-y} \mathrm{Ni}_{y} \mathrm{O}$. The values were estimated from the Rietveld refinements for the pristine and charged samples and from literatures for $\mathrm{NiO}$ [1] and $\mathrm{MgO}$ [2]. 
No change in peak positions of $\mathrm{Ni} / \mathrm{MgO}$ phase confirms chemical inactivity evidenced by the same peak position in Figure S4.

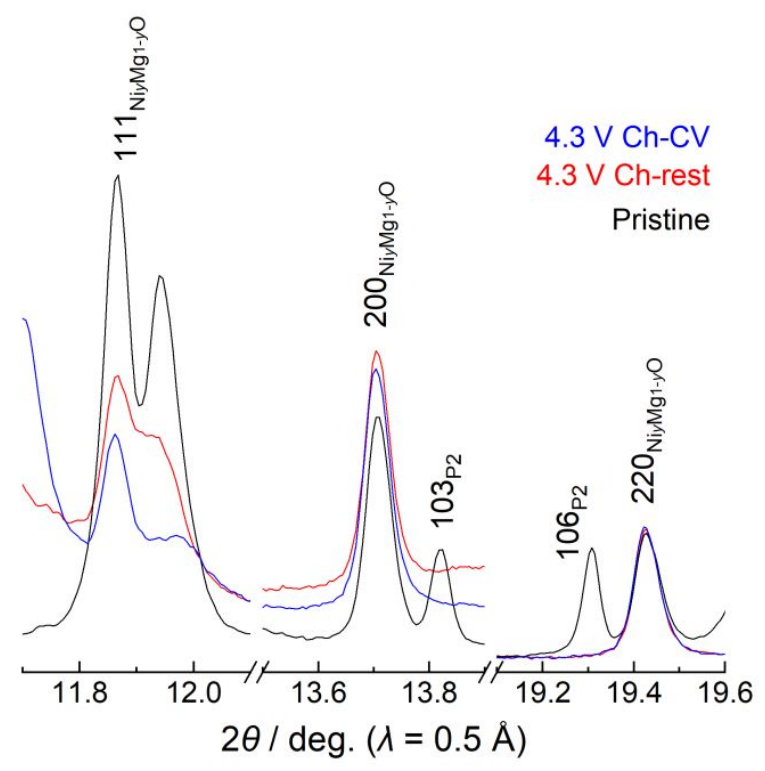

Figure S4. Synchrotron XRD patterns of the pristine and charged electrodes in the enlarged diffraction angles for the $\mathrm{Ni} / \mathrm{MgO}$ phase.

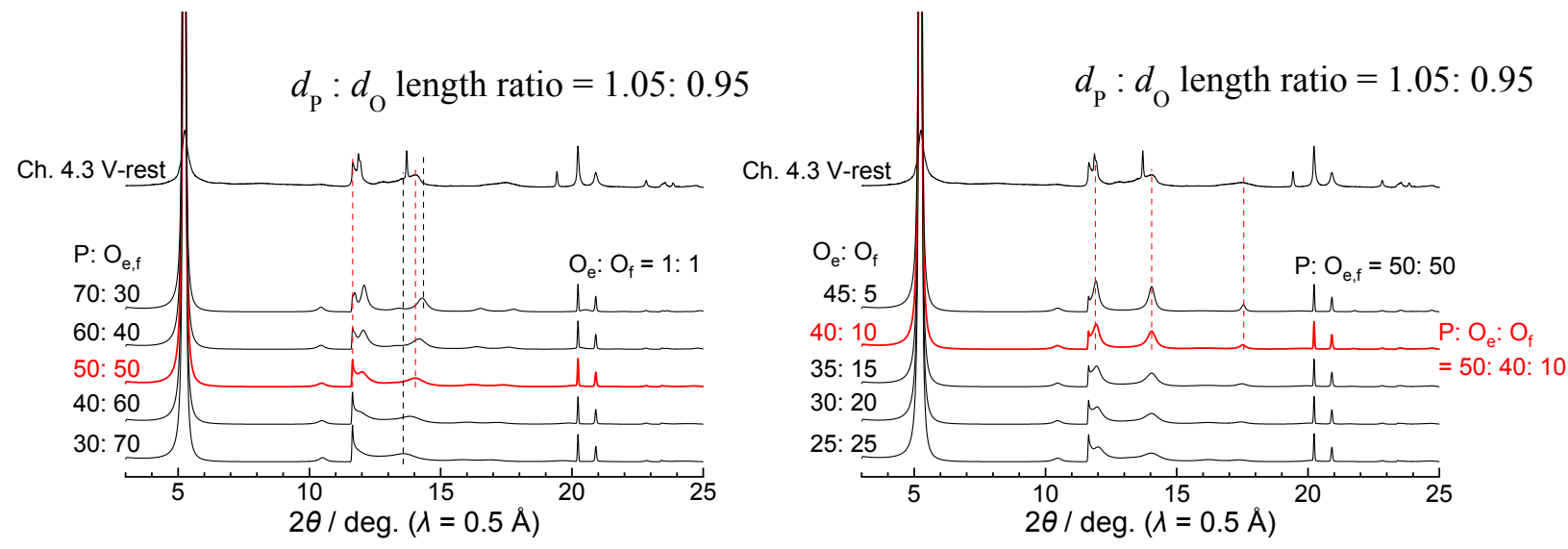

Figure S5. DIFFaX simulated pattern for OP2 phase in case of Ch-rest sample. On the left, $\mathrm{O}_{\mathrm{e}}$ and $\mathrm{O}_{\mathrm{f}}$ phases are in 1:1 ratio. After selecting the 50:50 ratio, the 50:40:10 ratio for $\mathrm{P}: \mathrm{O}_{\mathrm{e}}: \mathrm{O}_{\mathrm{f}}$ phases has been identified to be the optimal (right). 

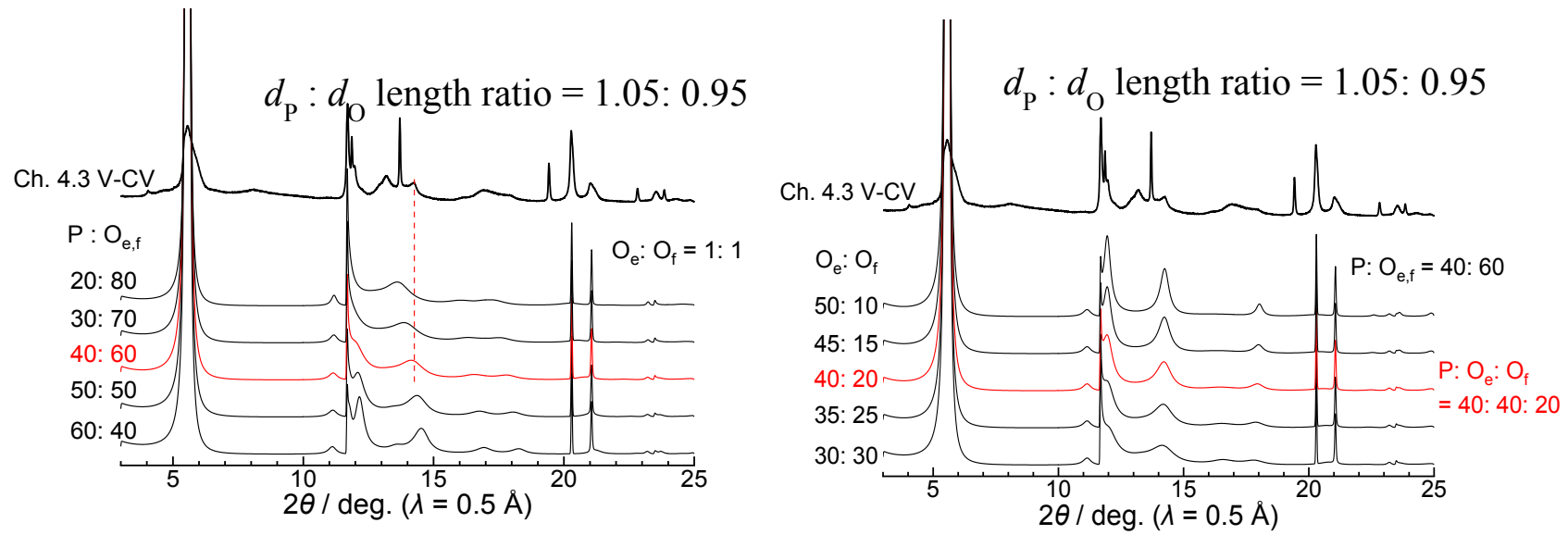

Figure S6. DIFFaX simulated pattern for OP2(1) phase in case of Ch-CV sample. On the left, $\mathrm{O}_{\mathrm{e}}$ and $\mathrm{O}_{\mathrm{f}}$ phases are in 1:1 ratio. After selecting the 40:60 ratio, the 40:40:20 ratio for $\mathrm{P}: \mathrm{O}_{\mathrm{e}}: \mathrm{O}_{\mathrm{f}}$ phases has been identified to be the optimal (right).
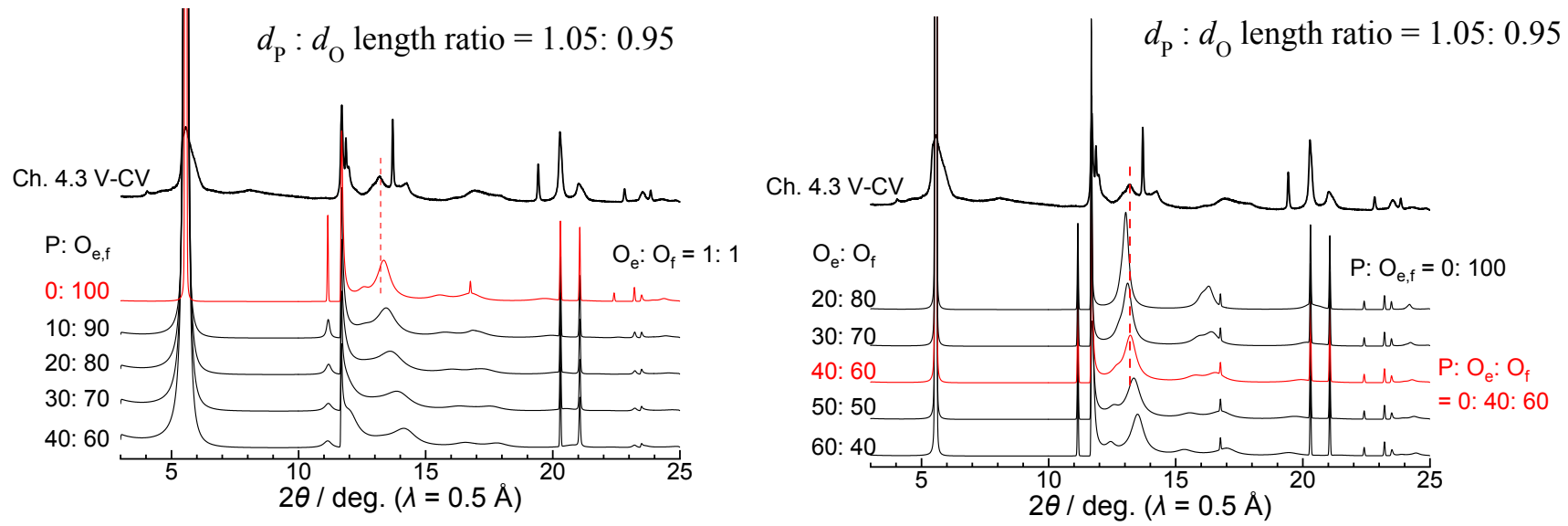

Figure S7. DIFFaX simulated pattern for OP2(2) phase in case of Ch-CV sample. On the left, $\mathrm{O}_{\mathrm{e}}$ and $\mathrm{O}_{\mathrm{f}}$ phases are in 1:1 ratio. After selecting the 0:100 ratio, the $0: 40: 60$ ratio for $\mathrm{P}: \mathrm{O}_{\mathrm{e}}: \mathrm{O}_{\mathrm{f}}$ phases has been identified to be the optimal (right). 


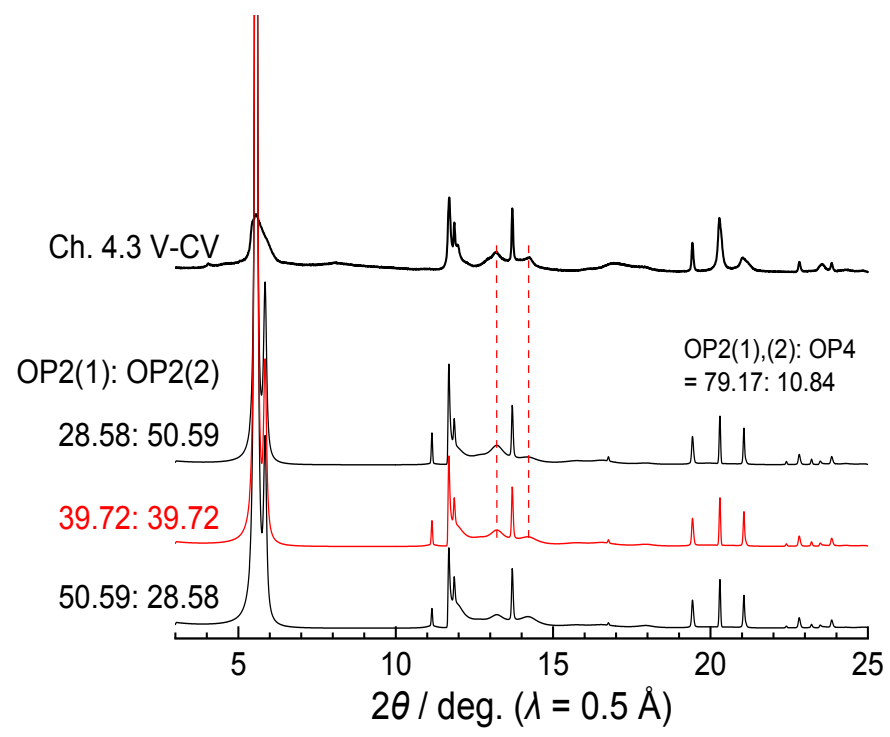

$\mathrm{OP} 2(1) ; \mathrm{P}: \mathrm{O}_{\mathrm{e}}: \mathrm{O}_{\mathrm{f}}=40: 40: 20$

$\mathrm{OP} 2(2) ; \mathrm{P}: \mathrm{O}_{\mathrm{e}}: \mathrm{O}_{\mathrm{f}}=0: 40: 60$

OP4; P: $\mathrm{O}_{1}: \mathrm{O}_{2}=60: 20: 20$

OP2(1): OP2(2): OP4

$=39.59: 39.59: 10.84$

Figure S8. DIFFaX simulated pattern for Ch-CV sample. Considering the OP4 (P: $\mathrm{O}_{1}: \mathrm{O}_{2}=60: 20$ : 20), OP2(1) (P: $\left.\mathrm{O}_{\mathrm{e}}: \mathrm{O}_{\mathrm{f}}=40: 40: 20\right)$, and OP2(2) (P: $\left.\mathrm{O}_{\mathrm{e}}: \mathrm{O}_{\mathrm{f}}=0: 40: 60\right)$ phases in a $10.84: 39.59$ : 39.59 ratio, respectively, the optimal simulated pattern is obtained.

\section{References}

[1] Takemura, Y.; Morita, Y.; Yamamoto, K.-i., Bulletin of The Japan Petroleum Institute 1967, 9, $13-18$

[2] Boiocchi, M.; Caucia, F.; Merli, M.; Prella, D.; Ungaretti, L., Eur. J. Mineral. 2001, 13, (5), $871-881$ 